\title{
Efeito da temperatura sobre a severidade de Plasmodiophora brassicae*
}

\author{
Daniel Dias Rosa ${ }^{1,2}$; Marco Antonio Basseto; Edson Luiz Furtado ${ }^{1,2}$
}

${ }^{1}$ Universidade Estadual Paulista - UNESP, Faculdade de Ciências Agronômicas - FCA, Departamento de Produção Vegetal - Setor Defesa Fitossanitária, CP 237, CEP: 18603-970 Botucatu, SP. ${ }^{2}$ Bolsista do CNPq. * Parte da Tese de doutorado do primeiro autor. Autor para correspondência: Daniel Dias Rosa (ddrosa@gmail.com)

Data de chegada: 30/02/2008. Aceito para publicação em: 29/07/2010.

\section{RESUMO}

Rosa, D.D., Basseto, M.A., Furtado, E.L. de. Efeito da temperatura sobre a infecção de Plasmodiophora brassicae. Summa Phytopathologica, v.36, n.3, p.240-243, 2010.

A temperatura é um dos parâmetros importantes para que ocorra a infecção, processo primordial para que haja doença, visando-se verificar a influência deste parâmetro sobre a severidade de Plasmodiophora brassicae em plantas de couve chinesa Pak choi, montou-se testes de infecção em temperaturas variando de 5 em $5^{\circ} \mathrm{C}$, indo de 10 a $40^{\circ} \mathrm{C}$, e observou-se uma redução da severidade da doença nas mudas de 28 dias de idade, nas temperaturas acima de $30^{\circ} \mathrm{C}$, verificando-se que nas temperaturas de 20 a $25^{\circ} \mathrm{C}$ a ocorrência da condição ótima para o desenvolvimento da doença.

Palavras-chave adicionais: hérnia-das-cruciferas, patógenos habitantes do solo

\section{ABSTRACT}

Rosa, D.D., Basseto, M.A., Furtado, E.L. de. Effect of temperature on Plasmodiophora brassicae infection.Summa Phytopathologica, v.36, n.3, p.240-243, 2010.

Temperature is an important parameter for infection and plant desease development. In order to determine the influence of temperature on the severity of clubroot caused by Plasmodiophora brassicae in Pak choi Chinese cabbage plants, infection tests were carried out under temperatures set at $5^{\circ} \mathrm{C}$ increments, from 10 to $40^{\circ} \mathrm{C}$. A reduction in severity of the disease was observed during the analysis of results in 28-day-old seedlings, at temperatures above $30^{\circ} \mathrm{C}$. The optimal temperature for disease development and crop growth were from 20 to $25^{\circ} \mathrm{C}$. It was observed that at this temperature range inoculated seedling presented $26 \%$ less dry matter than noninoculated seedlings, thus demonstrating a direct effect of clubroot on plant dry matter accumulation.

Keywords: clubroot, soilborne pathogen

As espécies da família Brassicaceae cultivadas no mundo apresentam inúmeros problemas com patógenos e Plasmodiophora brassicae é considerado o patógeno de solo mais importante para estas culturas, pois além de atacar espécies silvestres, como Arabidopsis thaliana na Europa, também ataca as mais importantes espécies cultivadas de Brassicaceas no mundo, Brassica oleraceae L. (Couve, repolho, Couve-flor, Brócolis, Couve de Bruxelas) Brassica napus L. e Brassica oleraceae L. var. pekinensis L. (Couve chinesa), fazendo com que haja uma grande insistência para o desenvolvimento de cultivares resistentes a $P$. brassicae (2).

Plasmodiophora brassicae foi identificado como agente causal da "hérnia das crucíferas" por Woronin em 1878, sendo que existem relatos da doença a partir do século XI, mas somente em 1930 Cook e Swartz relataram o ciclo de vida do patógeno e com isso o ciclo infeccioso da doença (9). A doença apresenta distribuição cosmopolita (8), mas observa-se uma maior ocorrência em regiões semi-tropicais ou temperadas, regiões onde a temperatura nas épocas de cultivo raramente ultrapassam as máximas de 25 a $27^{\circ} \mathrm{C}$ e mínimas de 10 a $15^{\circ} \mathrm{C}$. No Brasil o patógeno foi constado pela primeira vez em 1965 (4) e a partir daí pode ser encontrado nas regiões sul e sudeste, devido ao grande cultivo de brassicas nestas áreas e por elas apresentarem características climáticas favoráveis ao patógeno, como temperaturas mais amenas e umidade alta durante todo o ano o que auxilia no desenvolvimento da doença, apesar de se haver relatos da doença em plantas de agrião e rúcula na região centro-norte, uma região caracterizada por temperatura mais elevadas, com temperaturas de até $35^{\circ} \mathrm{C}$, e baixa umidade relativa (1), mas pode-se verificar uma baixa quantidade de relatos nessas condições climáticas.

Com base nessas observações objetivou-se estudar o efeito na temperatura sobre a severidade do protozoa Plasmodiophora brassicae sobre plantas de couve chinesa cultivar Pak Choi, susceptível ao patógeno, em condições de temperatura, umidade e luminosidade controlada.

O experimento utilizou-se do isolado PB12, coletado em planta de Brócolos na região de São José do Rio Pardo e mantido na micoteca do Laboratório de Patógenos de Solo, da Faculdade de Ciências Agronômicas - FCA, da Universidade Estadual Paulista "Julio de Mesquita" - UNESP, Campus Botucatu. O teste do efeito da temperatura sobre a infecção de Plasmodiophora brassicae foi montada utilizando-se de sete temperaturas, $10,15,20,25,30,35$ e $40^{\circ} \mathrm{C}$, as quais corresponderam aos tratamentos, sendo organizados em 2 blocos, recebendo delineamento ao acaso, dentro de cada tratamento, utilizouse seis repetições, sendo cada repetição composta por um copo plástico de $500 \mathrm{~mL}$, contendo substrato orgânico Plantimax HT, onde foram plantadas 5 mudas germinadas, contando ainda com o mesmo delineamento para o tratamento controle para cada tratamento, o qual 
não foi inoculado. O processo de inoculação das plantas se deu utilizando-se $3 \mathrm{~mL}$ de uma suspensão de $10^{6}$ esporo/mL distribuídos na região do colo das mudas de 5 dias de idade, esta suspensão foi obtida da trituração de 40 gramas de galhas coletadas, adicionadas a $200 \mathrm{~mL}$ de água destilada esterilizada, sendo triturada em um liquidificador por 30 segundos. Utilizou-se de uma escala modificada para se verificar os efeitos da temperatura sobre a infecção, esta escala se baseia em $0=$ raízes sadias; $1=$ redução de raízes com leve intumescimento das raízes; $2=$ redução de raízes com a presença de galhas e 3 = presença de galhas e ausência de raízes. Avaliou-se individualmente cada muda da repetição, calculando-se um valor médio da severidade por repetição utilizando-se a formula proposta por Kuginuki et al. (1999), índice de agressividade (IA) $=\left(1 n_{1}+2 n_{2}+3 n_{3}\right)$ $\mathrm{x} 100 / 3 N_{t}$, onde $n 1$ ao $n 3$ é o número de plantas dentro das respectivas notas e $N t$ é o número de plantas testadas. As plantas foram mantidas por 28 dias em câmaras de germinação, do tipo BOD, com fotoperíodo de 12 horas de luz e com umidade relativa sempre acima de $80 \%$.

Avaliou-se também o efeito sobre o peso seco das mudas, calculando-se o peso seco das mudas infectadas e não infectadas em cada tratamento. Todos os resultados foram analisados mediante o teste $\mathrm{F}$ entre as regressões lineares para cada tratamento.

Pode-se observar que em temperatura altas, $35^{\circ} \mathrm{C}$, a severidade de P. brassicae apresenta-se alterada, ocasionando uma redução dos sintomas observados, este fato também é observado nas temperaturas de 10 e $30^{\circ} \mathrm{C}$ (Figura 1 ). Nas temperaturas de $10,15,25$ e $30^{\circ} \mathrm{C}$ não observa-se diferença significativa nos sintomas, mas em valores absolutos verifica-se que a doença é favorecida nas temperaturas entorno de $20^{\circ} \mathrm{C}$, obtendo uma nota média de 1,87 , na escala de severidade (Figura 1). Quando analise-se o efeito da severidade da doença no peso seco das plantas, neste caso nas mudas de couve chinesa Pak Choi, verifica-se que na faixa de temperatura mais propicias ao desenvolvimento de doença, de 15 a $30^{\circ} \mathrm{C}$, é justamente onde verificase a maior redução do peso seco das plantas, diminuição média de $27 \%$ do peso seco da mudas nesta faixa (Figura 1), fato esse que faz com que haja uma grande quebra de produção em áreas infestadas, levando o agricultor a grandes perdas, visto que mesmo havendo um nível razoável de crescimento das plantas, esta plantas, possivelmente, estarão mais susceptíveis a outras doenças, possivelmente elevando o custo de produção.

Na medida, observa-se uma redução média de 29,3\% do peso seco das mudas, inoculadas para as não inoculadas (Figura 1). Na analise das curvas do peso seco, inoculada e não inoculada, submetida ao teste $F$ verifica-se que há diferença significativa $(P>0,05)$ entre as curvas.

Nas temperaturas mais propicias ao desenvolvimento da doença, de 15 e $20^{\circ} \mathrm{C}$, foi possível observar o intumescimento das radículas e a presença de pequenas galhas (Figura 1), demonstrando assim que estas temperaturas podem ser consideradas ideais para o desenvolvimento da doença, visto que também é a faixa onde se observa o maior peso seco das plantas, tanto infectadas com não infectadas, apresentando diferenças entre elas, e com uma diminuição de $26,3 \%$ do peso seco das mudas infectadas para as não infectadas (Figura 1), este fato podem contribuir na facilidade de avaliações visuais na procura por plantas resistentes a doença nos programas de melhoramento.

Observando-se o comportamento gráfico das notas medias de severidades e do peso seco das mudas, inoculadas e não inoculadas, verifica-se que há semelhança entre as curvas (Figura 1), sendo que a regressão dos valores médios de severidade, em notas, com as

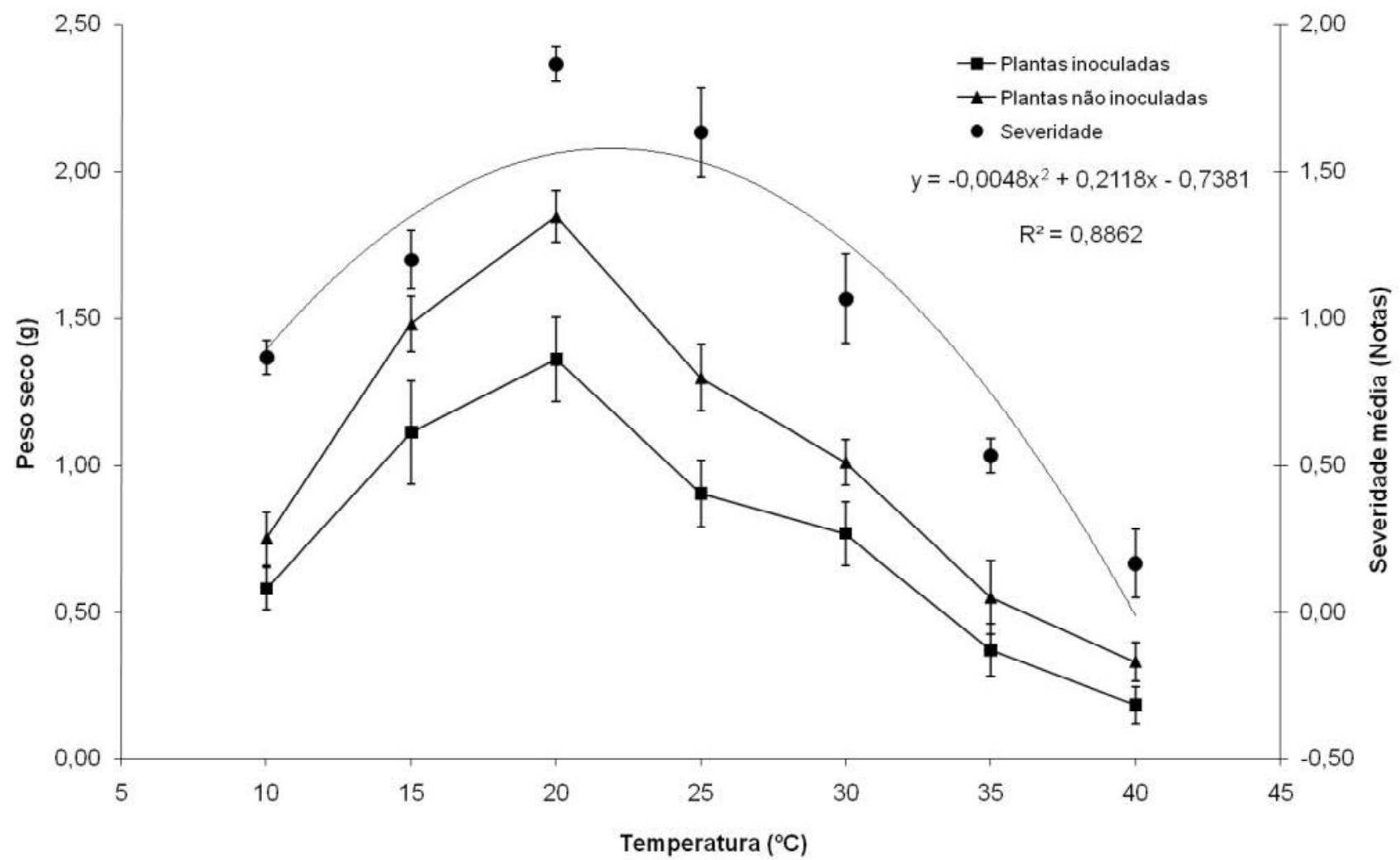

Figura 1. Severidade média, em notas, de Plasmodiophora brassicae em plantas de couve chinesas mantidas em diferentes temperaturas de desenvolvimento e peso seco, médio, das plantas cultivadas nessas temperaturas, inoculadas e não inoculadas com o patógeno (Severidade média baseada na escala de notas, onde a nota $0=$ raízes sadias; $1=$ redução de raízes com leve intumescimento das raízes; $2=$ redução de raízes com a presença de galhas e 3 = presença de galhas e ausência de raízes). 


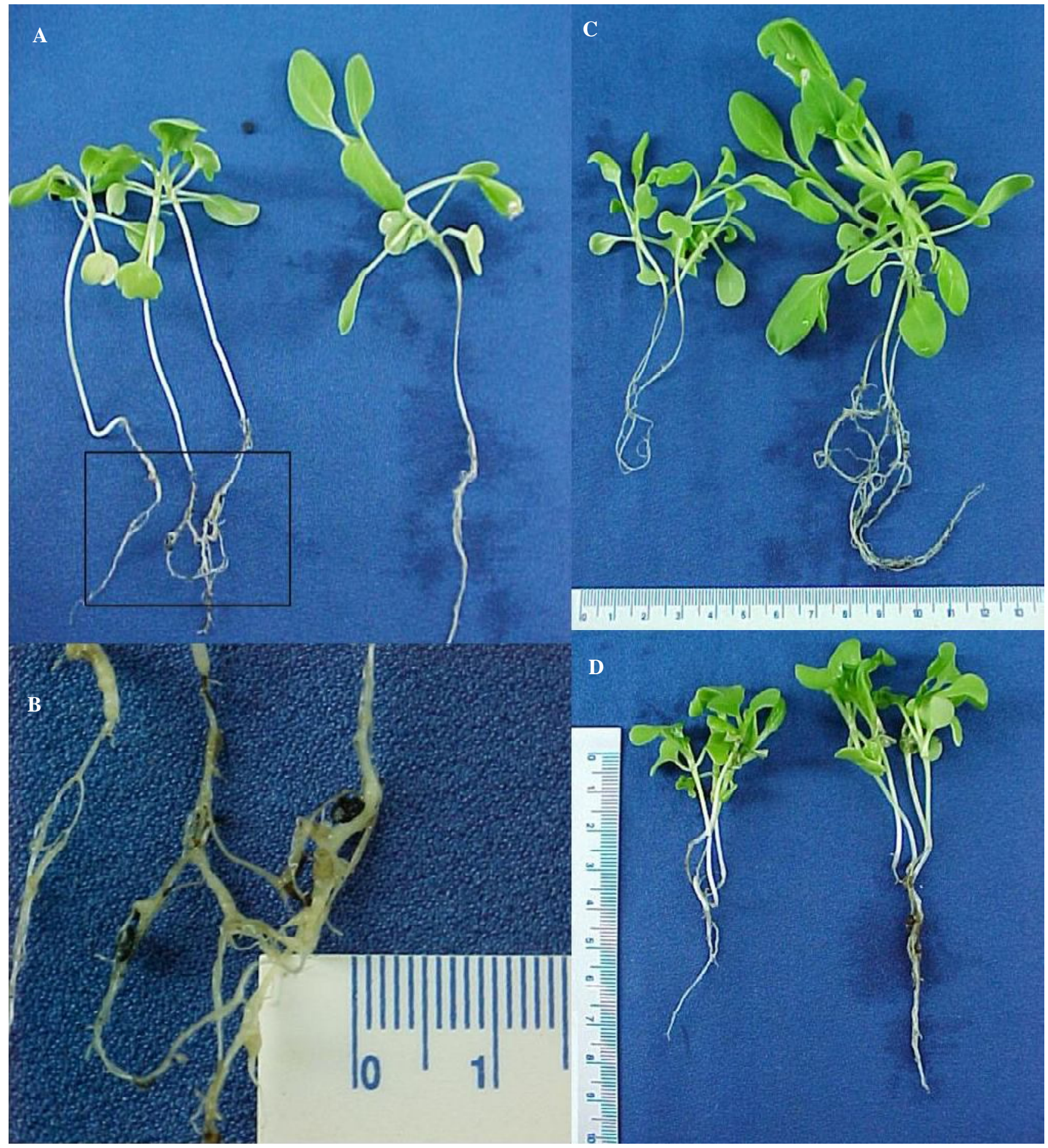

Figura 1. Plantas de Couve chinesas inoculadas e não inoculadas com Plasmodiophora brassicae; A - Plantas mantidas a $15^{\circ} \mathrm{C}$, por 28 dias, presença de galhas nas raízes e redução de raízes na plantas inoculada (esquerda) e raízes sadias na planta não inoculadas (direita); B - Presença de pequenas galhas e intumescimentos radiculares nas plantas inoculadas mantidas a $15^{\circ} \mathrm{C} ; \mathrm{C}$ - Plantas mantidas a $20^{\circ} \mathrm{C}$, por 28 dias, redução de raízes e de massa na plantas inoculada (esquerda) e planta sadia não inoculada (direita); D - Plantas mantidas a $30^{\circ} \mathrm{C}$, por 28 dias, redução de raízes e de massa na plantas inoculada (esquerda) em comparação a planta sadia não inoculada (direita).

temperaturas de infecção, observa-se um comportamento explicado por uma polinomial de segunda ordem, sendo expressa por $\mathrm{Y}=$ $0,0048 X^{2}+0,2118 X-0,7381$, onde $Y$ corresponde a severidade média da doença, em nota, e $X$ corresponde a temperatura de infecção e desenvolvimento da doença, em ${ }^{\circ} \mathrm{C}$, sendo que a equação apresentou um coeficiente de determinação, $\mathrm{r}^{2}=0,8862$, ou seja, a equação corresponde por $88,62 \%$ dos pontos obtidos (Figura 1).
Com base na polinomial de regressão, calculou-se a temperatura ótima de infecção e desenvolvimento da hérnia das crucíferas obtendo que $22^{\circ} \mathrm{C}$ é a temperatura ótima de infecção e desenvolvimento para Plasmodiophora brassicae junto a plantas de couve chinesa cv. Pak choi, nas condições testadas e com o isolado testado (Figura 1).

O fator ambiente é um dos alicerces do processo doença, sendo neste incluído a variável temperatura com uma das mais importantes 
variáveis para que haja o estabelecimento da relação entre o patógeno e o hospedeiro e com isso ocorra o processo doença, com base nesta observação, Gabrielson e Robak (6) relatam que a temperatura também é um fator imprescindível a ser considerado no processo de melhoramento das brassicas a resistência a Plasmodiophora brassicae, haja vista a grande diversidade de raças fisiológicas deste patógeno, das quais muitas são sensíveis a temperaturas elevadas, levando a uma hipovirulência destas raças devido a temperatura não ideal para elas. Fazendo com que, em muitos casos, o processo de melhoramento não seja devidamente avaliado perante a infecção destas raças, devido ao fato de não se adequar o ambiente a temperatura mais propicias para a infecção destas raças mais sensíveis a temperatura.

Este fato também pode ser observado empiricamente em alguns campos de produção de regiões mais quente ou em anos agrícolas mais quentes, verificando-se uma diminuição da severidade da doença no campo, aliado a isto, Dobson et al. (5) relatam que fatores na mistura de solo também influenciam muito sobre o processo, principalmente os valores de teor de água no solo, fator esse que tem correlação direta com a temperatura radicular das plantas, fazendo que haja uma diminuição nos valores de severidade nas plantas presentes em solos com uma menor carga de água.

Asamo et al. (2), em estudos de infecção da Plasmodiophora brassicae em raízes cultivadas in vitro, correlacionado às três temperaturas, 15,20 e $25^{\circ} \mathrm{C}$, verificaram que a temperatura de $20^{\circ} \mathrm{C}$ foi a mais propicia para a formação de galhas, formação de esporos de resistência e também foi a temperatura onde as galhas obtiveram o maior peso fresco, fatos esses que corroboram com os resultados obtidos neste trabalho, onde verifica-se o maior valor de severidade da doença a $20^{\circ} \mathrm{C}$. As informações apresentadas neste trabalho têm como intuito ajudar em futuros programas de melhoramento visando à resistência a Plasmodiophora brassicae, doença que vem crescendo e ganhando cada vez mais importância perante o setor produtivo, mostrando de forma clara que fatores ambientais são importantes pontos a serem considerados quando se almeja efetuar trabalhos visando resistência a fitopatógenos habitantes do solo.

\section{AGRADECIMENTOS}

Os autores agradassem a concessão de bolsa de estudo pelo Conselho Nacional de Desenvolvimento Científico e Tecnológico CNPq e a Fundação de Amparo a Pesquisa do Estado de São Paulo FAPESP, pela concessão do Auxilio Pesquisa, proc. N. 07/53834-5 e a empresa Sakata Seeds Co. pelo fornecimento de sementes. Ao saudoso Professor Nilton Luiz de Souza, pelo aprendizado e pelas sugestões no início deste trabalho.

\section{REFERÊNCIA BIBLIOGRÁFICAS}

1. Andrade, J.F.; Lima, M.L.P.; Nogueira, N.L. Plasmodiophora brassicae Wor. um novo patógeno infectando Eruca sativa Millcruciferae. In: XXXIV Congresso Brasileiro de Fitopatologia \& XI Congresso Latino-Americano de Fitopatologia, Fitopatologia Brasileira, São Pedro, v. 26 p. 446, 2001.

2. Asano, T; Kamada, A.; Kageyama, K. Susceptibility of hairy root lines of Brassica species to Plasmodiophora brassicae and an "in vitro" sub culture system. J. Gen. Pathol. 72:85-91, 2006.

3. Crute, I. R.; Gray, A. R.; Crisp, P.; Buczacki, S. T. Variation in Plasmodiophora brassicae and resistance to clubroot disease in Brassicas and allied crops - a critical review. Plant Breeding Abstracts, Amsterdam, v.50, n.1, p.91-104, 1980.

4. Café Filho, A.C.; Reifschneider, F.J.B. . Ocorrência de Plasmodiophora brassicae no Distrito Federal. Horticultura Brasileira, Brasília, v.4, n.1, p.37-38, 1986

5. Dobson, R.; Gabrielson, R.L.; Baker, A.S. Soil water matric potential requirements for root-hair and cortical infection of Chinese cabbage by Plasmodiophora brassicae, Phytopathology. St. Paul, v. 72, n.6, p. 1598-1600, 1982.

6. Gabrielson, R.L.; Robak, J. Temperature sensitivity of resistance to two pathotypes of Plasmodiophora brassicae in Brassica oleracea, Acta Agrobotanica. Londres, v.41, n. 2, p .237-243, 1988.

7. Kuginuki, Y.; Yoshikawa, H.; Hirai, M. Variation in virulence of Plasmodiophora brassicae in Japan tested with clubroot-resistant cultivars of Chinese cabbage (Brassica rapa L. ssp. pekinensis). European Journal of Plant Pathology. Wageningen,v.105, n.4, p. 327-332 May, 1999

8. Maringoni, A. C. Doenças das crucíferas. In: Kimati, H.; Amorim, L.; Rezende, J.A.M.; Bergamim Filho, A.; Camargo, L.E.A. (Org.) Manual de fitopatologia: doenças das plantas cultivadas. 4 ed ed. São Paulo: Editora agronômica Ceres, 2005, v. 2, p. 285-291.

9. Tommerup, I.C.; Ingram, D.S. The life cycle of Plasmodiophora brassicae Wor. in Brassica tissue cultures and in intact roots. New Phytologist, Wageninger, v.70, n.3, p.327-332, 1971. 